\title{
Effects of serratus anterior plane block for postoperative analgesia after thoracoscopic surgery compared with local anesthetic infiltration: a randomized clinical trial
}

This article was published in the following Dove Press journal:

Journal of Pain Research

\section{Guodong Chen ${ }^{1,2}$ \\ Yufang $\mathrm{Li}^{1,2}$ \\ Yixiao Zhang ${ }^{1,2}$ \\ Xiangming Fang' \\ 'Department of Anesthesiology and Intensive Care, The First Affiliated Hospital, School of Medicine, Zhejiang University, Hangzhou 310003, People's Republic of China; ${ }^{2}$ Department of Anesthesiology, Zhejiang Province Hospital of Integrated Traditional Chinese and Western Medicine, Hangzhou 310003, People's Republic of China}

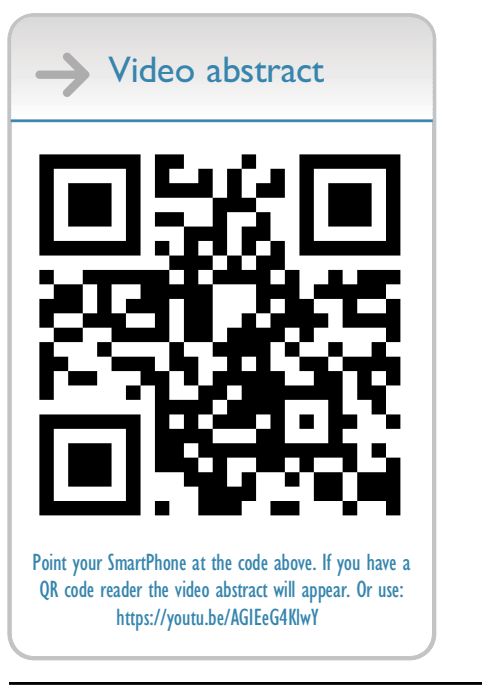

Correspondence: Xiangming Fang Department of Anesthesiology and Intensive Care Medicine, The First Affiliated Hospital of Zhejiang University School of Medicine, No. 79 Qing Chun Road, Hangzhou 310003, People's

Republic of China

Tel +8657188208006

Email xmfang@zju.edu.cn
Background: Serratus anterior plane (SAP) block is a relatively novel technique that can block the lateral cutaneous branches of the intercostal nerves as well as the long thoracic nerve.

Purpose: Our study aimed to evaluate the effects of SAP block on postoperative pain after thoracoscopic surgery compared with local anesthetic (LA) infiltration.

Patients and methods: Forty adult patients undergoing video-assisted thoracic surgery were randomized to receive either SAP block $(n=20)$ or LA infiltration of incision $(n=20)$. The primary outcome was postoperative visual analog scale (VAS) score at the 2nd, 8th, 16th, 24th, and 48th hour after surgery. The secondary outcomes were the consumption of sufentanil at 8 th, 16th, 24th hours postoperative. In addition, rescue analgesia, drug-related adverse effects after surgery was also analyzed.

Results: The SAP group showed lower VAS scores at the 2nd hour (at rest: SAP group 11 [8-13] vs LA group 28 [26-32], $P=0.01$; on coughing: 15 [13-18] vs 33 [26-38], $P=0.01$ ) and the 8 th hour (at rest: 13 [12-18] vs 36 [32-46], $P=0.01$; on coughing: 19 [16-23] vs 42 [36-53], $P=0.01)$ after surgery. Postoperative sufentanil consumption in the SAP group during $0-8 \mathrm{hrs}$ was significantly lower compared with the LA group $(P<0.01)$. The use of rescue analgesia was also significantly lower in the SAP group $(P=0.02)$ during $0-12$ hrs.

Conclusion: Compared to LA infiltration, ultrasound-guided SAP block may provide better pain relief as well as reduce opioid consumption after thoracoscopic surgery.

Keywords: serratus anterior plane block, thoracoscopic surgery, local anesthetic infiltration

\section{Introduction}

Effectiveness of pain management is an important component of enhanced recovery after thoracic surgery. ${ }^{1}$ Insufficient analgesia may lead to adverse outcomes, such as extended hospital stay, and increase patient medical expenses. Although new surgical procedures, such as video-assisted thoracic surgery (VATS), have considerable advantages compared with traditional thoracotomy, $29 \%$ of the patients still undergo postoperative pain, which makes achieving postoperative analgesia challenging. ${ }^{2,3}$ Thoracic epidural analgesia is widely regarded as the gold standard for thoracic analgesia however with a certain failure rate, which also is associated with complications such as spinal hematoma and higher in-hospital mortality. ${ }^{4,5}$ 
Therefore, a multimodal analgesic approach is recommended for management of pain. ${ }^{6}$ This approach usually combines local anesthetics (LAs) with opioid drugs, which is more acceptable to patients in minimally invasive surgery. ${ }^{7,8}$

Recently, the ultrasound-guided serratus anterior plane (SAP) block, which was first discovered by Blanco, this relatively novel approach can provide relief of hemithoracic pain by blocking the lateral cutaneous branches of the intercostal nerves. ${ }^{9}$ SAP technique has been described for perioperative analgesia in breast surgery, esophageal cancer surgery, and multiple rib fractures. ${ }^{10-12}$ However, only a few studies have evaluated the usefulness of the SAP block in perioperative pain management in patients indicated for thoracoscopic surgery. ${ }^{13,14}$ Therefore, our study aimed to compare the efficacy of SAP block and LA infiltration for perioperative analgesia in VATS.

\section{Materials and methods Design and participation}

This prospective randomized clinical trial was conducted after obtaining approval from the Chinese Clinical Trial Registry (ChiCTR1800019002) and approved by the local ethical committee (Reg. No.3209). A total of 59 patients were assessed for eligibility; the inclusion criteria were American Society of Anesthesiologist status I-II and age 18-65 years. Exclusion criteria included allergic constitution, severe cardiovascular or hepatorenal insufficiency, coagulation system disease, injection site infection, and morbid obesity (BMI $>40 \mathrm{~kg} / \mathrm{m}^{2}$ ). Finally, we enrolled 40 adult patients with pulmonary nodules undergoing elective thoracoscopic surgery from February 2017 to December 2017 at Zhejiang Province Hospital of Integrated Traditional Chinese and Western Medicine, China. Patients were randomly allocated to two groups using a computer-generated list of random numbers and sealed envelopes. The SAP group $(n=20)$ received the pre-emptive SAP block at T5-6, while the LA group $(n=20)$ received pre-emptive LA infiltration of incision. SAP block was performed by the only anesthesiologist, and thoracoscopic surgery was implemented by the same team of surgeons. Preoperatively, patients were informed about the use of visual analog scale (VAS) to assess the severity of pain, with a score from 0 to $100(0=$ no pain, $100=$ most severe pain), and the use of patient-controlled analgesia.

\section{Perioperative procedures}

No premedication was used. Standard monitoring was performed including noninvasive blood pressure monitoring and evaluation of pulse oxygen saturation ( $\mathrm{SpO} 2)$ and electrocardiography findings; an intravenous access was established. General anesthesia was induced with propofol $(2.5 \mathrm{mg} / \mathrm{kg})$, midazolam $(0.05 \mathrm{mg} / \mathrm{kg})$, sufentanil $(0.6 \mu \mathrm{g} /$ $\mathrm{kg})$, and rocuronium $(1 \mathrm{mg} / \mathrm{kg})$ to facilitate double-lumen tube intubation.

The ultrasound-guided SAP block was performed with the patient in the lateral position after induction of general anesthesia. We used ultrasound (SonoSite, Bothell, Washington) with a linear ultrasound transducer (10-12 $\mathrm{MHz}$ ). After skin disinfection, a probe was placed parallel to and between the 5th and 6th ribs in the mid-axillary region, for identification of the superficial latissimus dorsi muscles and deep anterior serratus muscles. Using a nerve block needle (22-G, 80-mm "Stimuplex D”, BBraun, Melsungen, Germany) and an in-plane technique (Figure 1A), $3 \mathrm{~mL}$ saline was injected above serratus anterior muscle. After confirming negative aspiration, $0.4 \mathrm{~mL} / \mathrm{kg} \quad 0.25 \%$ ropivacaine was injected (Figure 1B).

LA group received pre-infiltration of incision. VATS incision depends on the location of pulmonary nodules, singleincision (approximately $4 \mathrm{~cm}$ ) with $10 \mathrm{~mL} 0.25 \%$ ropivacaine or double-incision (approximately $3 \mathrm{~cm}+1 \mathrm{~cm}$ ) with $15 \mathrm{~mL}$ $(10 \mathrm{~mL}+5 \mathrm{~mL}) \quad 0.25 \%$ ropivacaine techniques are routinely used in our hospital. If the implementation of double-incision thoracoscopic surgery is inconvenient, we will adopt threeport strategy (approximately $3 \mathrm{~cm}+1 \mathrm{~cm}+0.5 \mathrm{~cm}$ ) with $17 \mathrm{~mL}$ $(10 \mathrm{~mL}+5 \mathrm{~mL}+2 \mathrm{~mL}) 0.25 \%$ ropivacaine for the placement of cameras and instruments.

Anesthesia was maintained using 1-1.2 MAC of sevoflurane, aiming for a bispectral index of 40-50. The doses of sevoflurane and sufentanil were also adjusted to maintain the mean arterial blood pressure (MAP) and heart rate (HR) within $80-120 \%$ of the preoperative values.
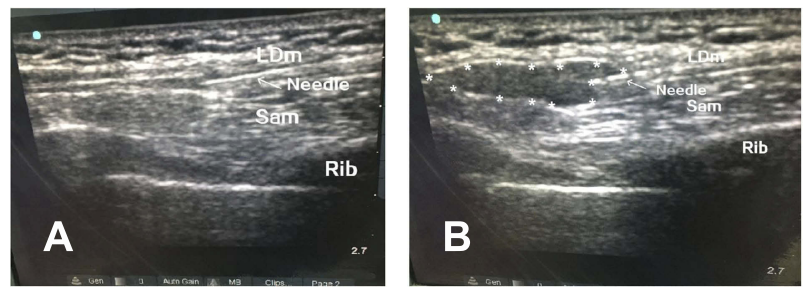

Figure I Using nerve block needle in-plane technique reached the position (A); after confirming negative aspiration, ropivacaine was injected (B). Note: *Ropivacaine.

Abbreviations: LDm, latissimus dorsi muscle; Sam, serratus anterior muscle. 
Hypotension (MAP $<80 \%$ of the baseline) was treated with ephedrine. Bradycardia ( $\mathrm{HR}<40 / \mathrm{min}$ ) was treated with atropine $0.5 \mathrm{mg}$. All patients received $0.1 \mathrm{mg} / \mathrm{kg}$ ondansetron and dynastat $40 \mathrm{mg}$ via intravenous injection before completion of the surgery. When the end-expiratory partial pressure of carbon dioxide was $<45 \mathrm{mmHg}$ and breath rate was $>12$ per minute, patients were extubated and transferred to the postoperative recovery room. The patients were then transferred to the post-anesthesia care unit (PACU). In the PACU, a PCA device (RehnMedtch, Jiangsu, China) was attached immediately.

The PCA regimen consisted of administration of sufentanil $0.5 \mu \mathrm{g} / \mathrm{mL}$ and saline at a total volume of $200 \mathrm{~mL}$. The PCA device was programmed to provide $2-\mu \mathrm{g}$ boluses on demand, with a lockout period of $10 \mathrm{mins}$ and no background infusion. If the pain relief was inadequate after a top-up dose (VAS score $>45$ ), a rescue opioid, by intravenous administration of $100 \mathrm{mg}$ tramadol, was provided by the acute pain service (APS) team. If the patient was still complaining of pain (VAS score $>55$ ), morphine 1 $\mathrm{mg}$ was given to the patient.

\section{Pain assessment}

The trained APS team evaluated and managed postoperative pain. All data were recorded by an investigator who was blinded to the group allocation and was not involved or present during surgery. Pain at rest and on coughing was recorded for each patient using the VAS (0-100) at the 2nd, 8th, 16th, 24th, and 48th hours after the surgery by the APS team. In addition, the APS service team was responsible for the maintenance of the PCA pump. The total 24 hrs consumption of sufentanil and rescue analgesics was recorded for every patient.

\section{Study outcomes}

Primary outcome measures were the VAS scores recorded at the 2nd, 8th, 16th, 24th, and 48th hours after the surgery. The secondary outcome measures were the amount of sufentanil consumption at the 8th, 16th, and 24th hours. In addition, postoperative nausea and vomiting (PONV), additional analgesic requirement, pulmonary complications, time of chest tube removal, length of hospital stay were recorded.

\section{Sample size}

The primary outcome was postoperative VAS score during $8 \mathrm{hrs}$. Sample size calculations were based on a pilot study (12 patients), the mean VAS score of the patients with LA infiltration of thoracoscopic surgery was estimated as 32.5, with a standard deviation (SD) of 6.5. We hypothesized that SAP block would be successful in reducing the VAS score by $30 \%$ (90\% power and a 5\% significance level), which would require 18 patients per group. To account for missing patient data, we included 20 patients in each group.

\section{Statistical analysis}

Pain scores and the consumption of sufentanil and rescue analgesics were analyzed by the Mann-Whiney U test. Other normally distributed data are presented as mean $\pm \mathrm{SD}$; these data were analyzed using an independent $t$-test, while categorical variables were analyzed by the $\chi^{2}$ test or Fisher exact test. $P<0.05$ was considered statistically significant for all tests. All the statistical analyses were performed using Statistical Package for the Social Sciences version 22.0 (SPSS Inc, Chicago, USA).

\section{Results}

\section{Patient characteristics and outcomes}

Between February 2017 and December 2017, 59 patients undergoing elective VATS were enrolled in our study. Three patients were excluded for the following reasons: age above 65 years $(n=2)$, and morbid obesity (BMI $>40$ $\left.\mathrm{kg} / \mathrm{m}^{2}\right)(\mathrm{n}=1)$. Further, six patients refused to participate. Ten patients were excluded from the final analysis because of mechanical obstruction of the PCA device $(n=2)$, change in operative plan $(n=4)$, withdrew the consent $(n=4)$. Consequently, data were analyzed for 20 patients in each group, as shown in Figure 2.

Patient background, clinical data, and perioperative details including age, sex, body weight, height, type of surgery, intraoperative sufentanil, and thoracoscopic incision were similar between the SAP and LA groups (Table 1).

\section{VAS scores at rest and on coughing}

VAS scores within 48 postoperative hours at rest and while coughing are shown in Figure 3. There was a significant reduction in the median (interquartile range, IQR) of VAS at rest in the SAP group compared with the LA group at $2 \mathrm{hrs}$ (SAP group vs LA group: 11 [8-13] vs 28 [26-32], $P<0.01)$ and at 8 hrs $(13[12-18)$ vs 36 [32$46], P<0.01)$. In addition, there was a significant reduction in the median (IQR) VAS score during coughing in the SAP group compared to the LA group at $2 \mathrm{hrs}$ (SAP 


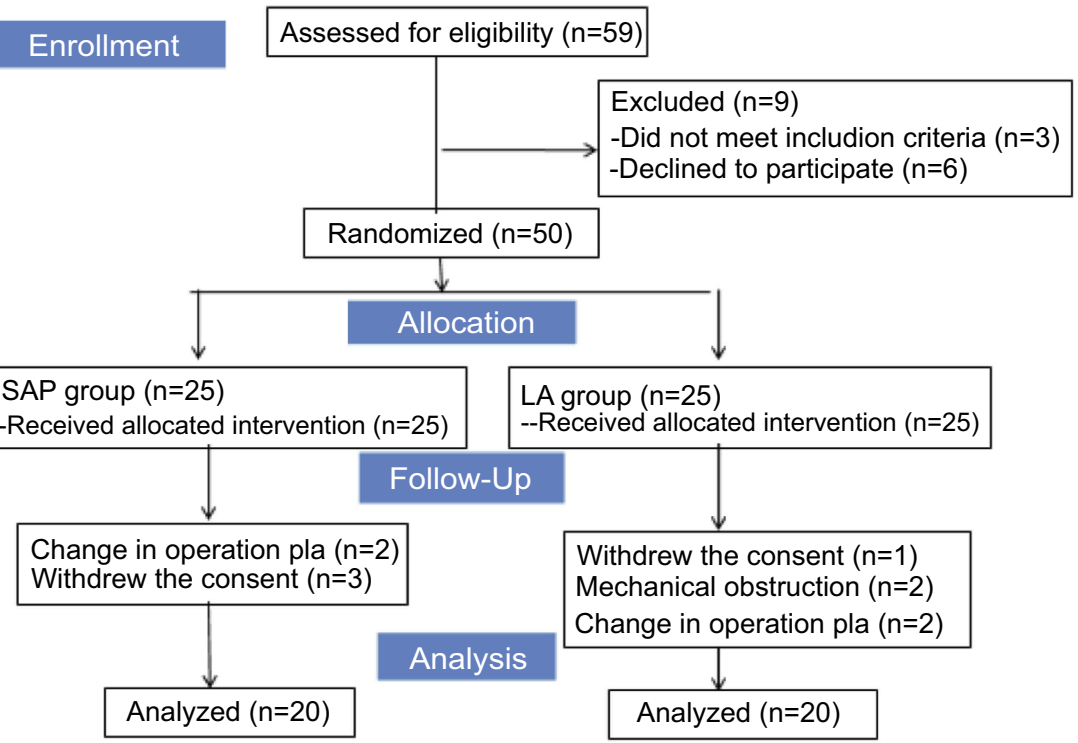

Figure 2 Patient flow diagram.

Abbreviations: SAP, serratus anterior plane; LA, local anesthetic.

Table I Patient characteristics and operation details

\begin{tabular}{|c|c|c|c|}
\hline & SAP $(n=20)$ & LA $(n=20)$ & $P$ \\
\hline Male, (n \%) & $\mathrm{II}(55)$ & $12(60)$ & 0.749 \\
\hline Age $(y)$, Mean \pm SD & $58.9 \pm 5.7$ & $57.1 \pm 6.2$ & 0.337 \\
\hline Height $(\mathrm{cm})$, Mean \pm SD & $165.1 \pm 7.9$ & $166.7 \pm 8.5$ & 0.528 \\
\hline Weight $(\mathrm{kg})$, Mean \pm SD & $63.9 \pm 7.8$ & $62.3 \pm 8.8$ & 0.544 \\
\hline ASA physical status (I/II) & $(10 / 10)$ & $(13 / 7)$ & 0.337 \\
\hline Operation time (mins), Mean \pm SD & $110.1 \pm 26.2$ & $107.8 \pm 30.3$ & 0.799 \\
\hline \multicolumn{4}{|l|}{ Type of surgery, (n \%) } \\
\hline Lobectomy & $12(60)$ & $\mathrm{II}(55)$ & 0.75 \\
\hline Segmentectomy & $8(40)$ & $9(45)$ & 0.75 \\
\hline \multicolumn{4}{|l|}{ Thoracoscopic incision, (n \%) } \\
\hline Single & $9(45)$ & $8(40)$ & 0.75 \\
\hline Double & $9(45)$ & II (55) & 0.53 \\
\hline Three & $2(10)$ & $\mathrm{I}(5)$ & 0.55 \\
\hline Intraoperative sufentanil (ug), Mean \pm SD & $43.5 \pm 5.2$ & $44.0 \pm 6.6$ & 0.79 \\
\hline Blood loss (mL) & $135 \pm 67.1$ & $155 \pm 84 . \mid$ & 0.41 \\
\hline Urine output (mL) & $460 \pm 162.7$ & $427.5 \pm 147.9$ & 0.52 \\
\hline
\end{tabular}

Note: Continuous variables with normal distribution are presented as mean \pm standard deviation (SD), and categorical variables are presented as $\mathrm{n}$ (\%).

Abbreviations: SAP, serratus anterior plane; LA, local anesthetic; ASA, American Society of Anesthesiologists.

group vs LA group: 15 [13-18] vs 33 [26-38], $P<0.01)$ and at $8 \mathrm{hrs}(19$ [16-23] vs 42 [36-53], $P<0.01)$. However, it was not significantly different in both groups at 16,24 , and $48 \mathrm{hrs}$ after surgery.

\section{Opioid consumption after surgery}

The opioid consumption in the SAP group was $6(2-8) \mu \mathrm{g}$, which was significantly lower than that in the LA group (18 [12-26] $\mu \mathrm{g}, P<0.01$ ), during $0-8 \mathrm{hrs}$ postoperatively. 


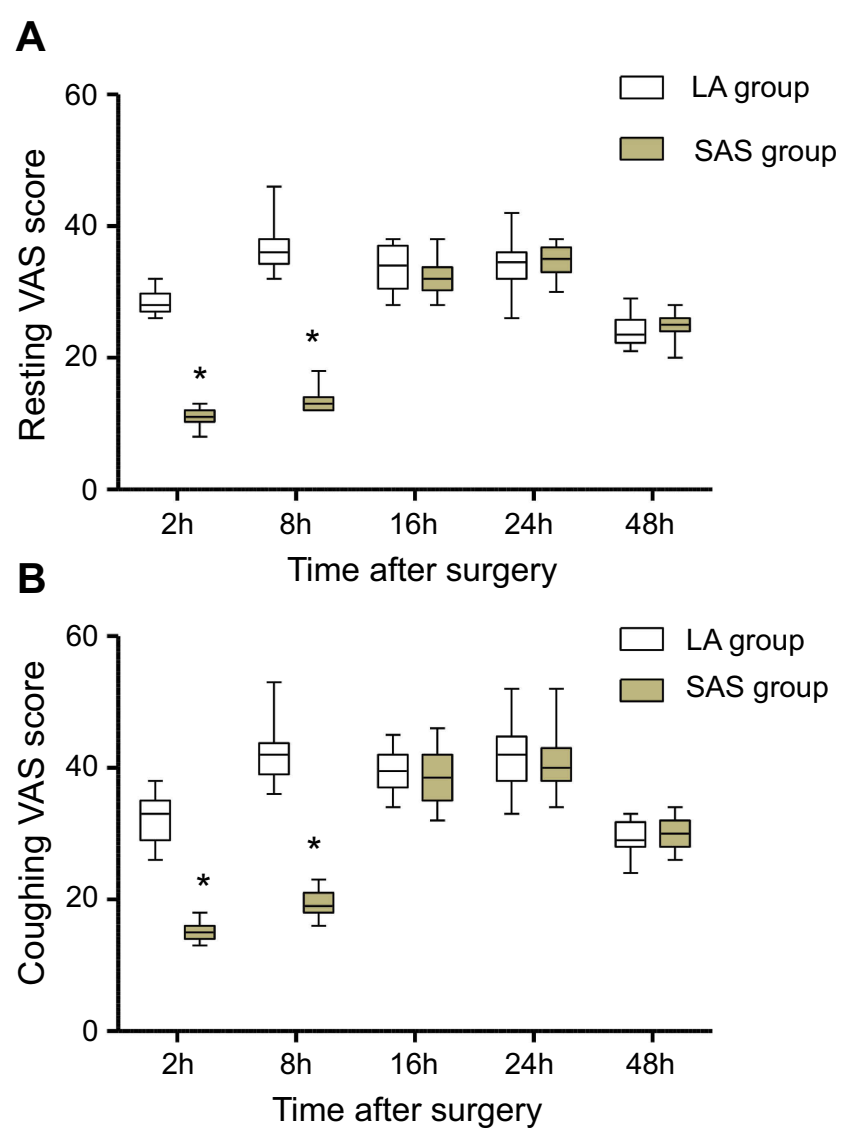

Figure 3 Postoperative pain scores during the first $24 \mathrm{hrs}$ after thoracoscopic surgery. Note: *Statistically significant.

Abbreviations: SAP, serratus anterior plane; LA, local anesthetic.

Comparable doses of sufentanil were administered to the two groups at 8-16 and 16-24 hrs (Figure 4).

\section{Rescue analgesia}

The dose of tramadol administered was significantly lower in the SAP group during 0-12 hrs (100 [0-200] mg vs 200

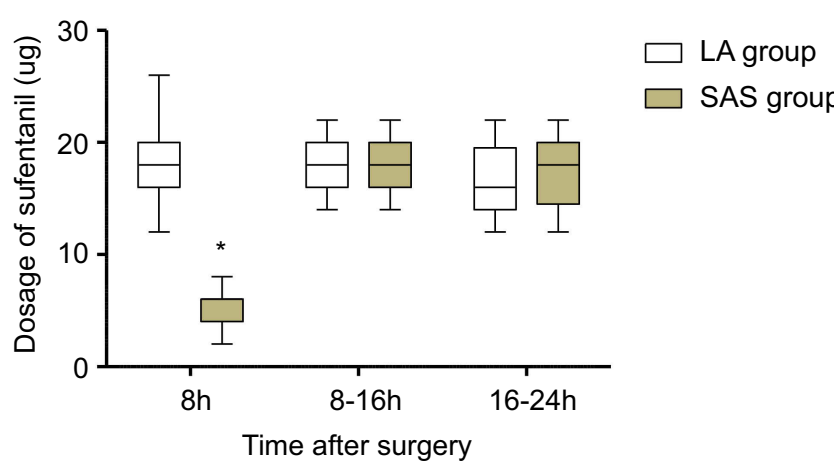

Figure 4 The time course of opioid consumption postoperative. Note: *Statistically significant.

Abbreviations: SAP, serratus anterior plane; LA, local anesthetic.
Table 2 The dose of tramadol postoperative

\begin{tabular}{|l|l|l|l|}
\hline & SAP (n=20) & LA (n=20) & P-value \\
\hline $\begin{array}{l}\text { Rescue tramadol (mg), } \\
\text { median } \\
\text { (interquartile range, IQR) }\end{array}$ & & & \\
$0-12$ hrs & $100(0,200)$ & $200(0,400)$ & $0.02^{*}$ \\
I2-I24 hrs & $100(0,200)$ & $100(0,200)$ & 0.64 \\
$24-48$ hrs & $0(0,100)$ & $0(0,100)$ & 0.74 \\
\hline
\end{tabular}

Note: * Statistically significant $(p<0.05)$.

Abbreviations: SAP, serratus anterior plane; LA, local anesthetic.

[0-400] mg, $P=0.02$ ). Comparable rescue analgesia was implemented to the two groups at $12-24$ and $24-48 \mathrm{hrs}$ (Table 2).

\section{Postoperative data}

There was a significant reduction in the incidence of PONV in the SAP group (10\%), which was lower than that in the LA group (40\%), but there was no significant difference $(P=0.07)$. The incidence of atelectasis and pneumonia, time of chest tube removal, and length of hospital stay were comparable between the groups (Table 3).

\section{Discussion}

Our current randomized trial firstly compared the SAP block with local wound infiltration after thoracoscopic surgery to present the effectiveness of the SAP block. The SAP block provided a superior pain relief in the early postoperative period, with significantly lower pain scores and less opioid consumption up to $8 \mathrm{hrs}$ compared with LA infiltration.

Operative wound, muscle splitting, chest tube stimulation, and visceral pain are important components of postthoracoscopic pain. Accordingly, managing multiple pain after thoracoscopic surgery is necessary. However, most patients complain about the pain of the chest tube after operation. The chest tube directly stimulates the contraction

Table 3 Postoperative data

\begin{tabular}{|l|l|l|l|}
\hline & $\begin{array}{l}\text { SAP } \\
(\mathbf{n = 2 0 )}\end{array}$ & $\begin{array}{l}\text { LA } \\
(\mathbf{n = 2 0 )}\end{array}$ & P-value \\
\hline Nausea and vomiting, n (\%) & $2(10)$ & $8(40)$ & 0.07 \\
Atelectasis, n (\%) & $0(0)$ & $I(5)$ & $\mathrm{I}$ \\
Pneumonia, n (\%) & $\mathrm{I}(5)$ & $\mathrm{I}(5)$ & $\mathrm{I}$ \\
Time of chest tube removal (d), & $3.7 \pm 0.9$ & $3.6 \pm 1 . \mathrm{I}$ & 0.87 \\
Mean \pm SD & & & \\
Length of hospital stay (d) & $10.6 \pm 2.4$ & $\mathrm{II} .6 \pm 2.0$ & 0.19 \\
\hline
\end{tabular}

Abbreviations: SAP, serratus anterior plane; LA, local anesthetic; d, days. 
and spasm of the serratus anterior muscle, which aggravates the pain. ${ }^{15}$ Kwon et al, reported that improving anterior serratus muscle relaxation by blocking the long thoracic nerve (LTN) could reduce pain after thoracoscopic surgery. ${ }^{15}$ Traditionally, SAP block can block the cutaneous branch of intercostal nerve to relieve postoperative pain. ${ }^{16}$ Fortunately, a cadaver study conducted by Varghese et al, discovered that SAP block could also make dye spread sufficiently to cover the LTN. ${ }^{16,17}$ By contrast, the LTN is not blocked sufficiently by LA infiltration. Hence, we theorize that SAP block is superior to LA infiltration.

Pre-emptive wound infiltration in VATS has been shown to improve postoperative pain. $^{8}$ Pre-emptive analgesia can block up pain signal transduction pathways and reduce central and peripheral sensitization, thus leading to a complex physiological change. ${ }^{18,19}$ Wound infiltration displays undoubtedly simple, effective with few complications that have already been applied in many surgeries, especially in minimally invasive surgery. ${ }^{7,8}$

Interestingly, increasing attentions were paid to the novel technique - SAP block that was first described by Blanco in volunteers who obtained a superior block from T2 to T9 lasting 750-840 mins. ${ }^{9}$ It is valuable to mention that Okmen et al, reported that SAP group reduced pain scores and tramadol consumption in VATS compared with the control group. ${ }^{13}$ Meanwhile, a pilot study conjectured SAP block potentially becomes an alternative technique for epidural analgesia in esophagectomy, ${ }^{10}$ but still remain randomized trials to further prove. In 2018, a randomized trial proved SAP block can reduce pain and opioid use compared to the sham procedure after thoracoscopic lung surgery. ${ }^{14}$ However, they did not compare with the local wound infiltration. To our best knowledge, our current study first time evaluated pre-emptive SAP blockade vs pre-emptive infiltration in thoracoscopic surgery.

Currently, there is a lack of uniform evaluation criterion for the volume and concentration of SAP block. Kunigo et al, performed SAP block for breast cancer surgery, the results showed that $40 \mathrm{~mL}$ of $0.375 \%$ ropivacaine effected in an extensive range than $20 \mathrm{~mL}^{20}$ However, the literatures involving the plasma concentration of SAP block remain poor. For safety, our study adopted Blanco's approach $(0.4 \mathrm{~mL} / \mathrm{kg} \quad 0.25 \%$ ropivacaine). In view of our result, the effectiveness of single SAP block was $8 \mathrm{hrs}$ postoperative, in which the duration of analgesia was consistent with Blanco's experiment.

We did not observe any adverse events associated with SAP block in this study. The technique for SAP block can be easily mastered by anesthesiologists without ultrasound experience. In our study, incidence of PONV did not show significant differences between the SAP and LA groups, which might attribute to the small sample size of our study. Patients receiving SAP block had a lower incidence of PONV. However, it is difficult to determine whether the PONV was caused by reduction in the dosage of sufentanil or excessive use of tramadol. Both groups did not show statistical significance in pulmonary complications (atelectasis and pneumonia) possibly due to the limited sample capacity in our study.

Some limitations of this study need to be considered. First, a control group is unavailable in our clinical study, as it was considered unethical by our Local Ethics Committee to perform a sham-SAP blocks or sham wound infiltration. Second, although we saw well diffusion of LAs under ultrasound, we failed to assess the sensory range and failure rate of SAP block after anesthesia. Finally, chronic pain should also be considered after thoracic surgery, while our study only recorded early postoperative pain in thoracic surgery and failed to follow-up further.

\section{Conclusion}

Our research shows that SAP block has advantages over local analgesia in thoracic surgery and may serve as a supplementary technique for thoracic analgesia.

\section{Ethical statement}

The authors declare that all patients gave written informed consent before initiation of the study protocol and was conducted in accordance with the Declaration of Helsinki. The study was approved by the Ethics Committee of Zhejiang Province Hospital of Integrated Traditional Chinese and Western Medicine (Reg. No. 3209).

\section{Data availability}

The corresponding author (xmfang@zju.edu.cn) or first author (chen8239598@126.com) will be ready to send all related data for any authority on request by an email message. The data will be available this way for up to 6 months after the paper is published.

\section{Disclosure}

The authors report no conflicts of interest in this work. 


\section{References}

1. Miralpeix E, Nick AM, Meyer LA, et al. A call for new standard of care in perioperative gynecologic oncology practice: impact of enhanced recovery after surgery (ERAS) programs. Gynecol Oncol. 2016;141(2):371-378. doi:10.1016/j.ygyno.2016.02.019

2. Neustein SM, McCormick PJ. Postoperative analgesia after minimally invasive thoracoscopy: what should we do? Can J Anesth. 2011;58(5):423-427. doi:10.1007/s12630-011-9475-9

3. Bayman EO, Parekh KR, Keech J, Selte A, Brennan TJ. A prospective study of chronic pain after thoracic surgery. Anesthesiology. 2017;126(5):938-951. doi:10.1097/ALN.0000000000001576

4. Hermanides J, Hollmann MW, Stevens MF, Lirk P. Failed epidural: causes and management. Brit J Anaesth. 2012;109(2):144-154. doi:10.1093/bja/aes214

5. Rosero EB, Joshi GP. Nationwide incidence of serious complications of epidural analgesia in the United States. Acta Anaesth Scand. 2016;60(6):810-820. doi:10.1111/aas.12702

6. Umari M, Carpanese V, Moroa V, et al. Postoperative analgesia after pulmonary resection with a focus on video-assisted thoracoscopic surgery. Eur J Cardio-Thorac. 2018;53(5):932-938. doi:10.1093/ ejcts/ezx413

7. Papagiannopoulou P, Argiriadou H, Georgiou M, Papaziogas B, Sfyra E, Kanakoudis F. Preincisional local infiltration of levobupivacaine vs ropivacaine for pain control after laparoscopic cholecystectomy. Surg Endosc. 2003;17(12):1961-1964. doi:10.1007/s00464-0029256-1

8. Sihoe AD, Manlulu AV, Lee TW, Thung KH, Yim AP. Pre-emptive local anesthesia for needlescopic video-assisted thoracic surgery: a randomized controlled trial. Eur J Cardio-thorac Surg. 2007;31 (1):103-108. doi:10.1016/j.ejcts.2006.09.035

9. Blanco R, Parras T, McDonnell JG, Prats-Galino A. Serratus plane block: a novel ultrasound-guided thoracic wall nerve block Anaesthesia. 2013;68(11):1107-1113. doi:10.1111/anae.2013.68. issue-11

10. Barbera C, Milito P, Punturieri M, Asti E, Bonavina L. Serratus anterior plane block for hybrid transthoracic esophagectomy: a pilot study. J Pain Res. 2017;10:73-77. doi:10.2147/JPR.S134133
11. Kunhabdulla NP, Agarwal A, Gaur A, Gautam SK, Gupta R, Agarwal A. Serratus anterior plane block for multiple rib fractures. Pain Physician. 2014;17(4):E553-E555.

12. Bouzinac A, Brenier G, Dao M, Delbos A. Bilateral association of pecs I block and serratus plane block for postoperative analgesia after double modified radical mastectomy. Minerva Anestesiol. 2015;81 (5):589-590.

13. Okmen K, Okmen BM. Evaluation of the effect of serratus anterior plane block for pain treatment after video-assisted thoracoscopic surgery. Anaesth Crit Care Pa. 2018;37(4):349-353. doi:10.1016/j. accpm.2017.09.005

14. Park MH, Kim JA, Ahn HJ, Yang MK, Son HJ, Seong BG. A randomised trial of serratus anterior plane block for analgesia after thoracoscopic surgery. Anaesthesia. 2018;73(10):1260-1264. doi:10.1111/anae.2018.73.issue-10

15. Kwon WK, Choi JW, Kang JE, et al. Long thoracic nerve block in video-assisted thoracoscopic wedge resection for pneumothorax. Anaesth Intens Care. 2012;40(5):773-779. doi:10.1177/0310057X1 204000504

16. Mayes J, Davison E, Panahi P, et al. An anatomical evaluation of the serratus anterior plane block. Anaesthesia. 2016;71(9):1064-1069. doi:10.1111/anae. 13549

17. Varghese L, Johnson M, Barbeau M, Rakesh SV, Magsaysay P, Ganapathy S. The Serratus Anterior Plane (SAP) block: an anatomical investigation of the regional spread of anesthetic using ultrasound-guided injection. Faseb J. 2016;30(560):1.

18. Woolf CJ. Evidence for a central component of post-injury pain hypersensitivity. Nature. 1983;306(5944):686-688. doi:10.1038/ 306686a0

19. Woolf CJ, Salter MW. Neuroscience - neuronal plasticity: increasing the gain in pain. Science. 2000;288(5472):1765-1768. doi:10.1126/ science.288.5472.1765

20. Kunigo T, Murouchi T, Yamamoto S, Yamakage M. Injection volume and anesthetic effect in serratus plane block. Region Anesth Pain M. 2017;42(6):737-740. doi:10.1097/AAP.0000000000000649
Journal of Pain Research

\section{Publish your work in this journal}

The Journal of Pain Research is an international, peer reviewed, open access, online journal that welcomes laboratory and clinical findings in the fields of pain research and the prevention and management of pain. Original research, reviews, symposium reports, hypothesis formation and commentaries are all considered for publication. The manuscript management system is completely online and includes a very quick and fair peer-review system, which is all easy to use. Visit http:// www.dovepress.com/testimonials.php to read real quotes from published authors. 